\title{
New Insights Into Physiological and Pathophysiological Functions of Stanniocalcin 2
}

\author{
Aditya D. Joshi* \\ Department of Pharmacology and Toxicology, University of Texas Medical Branch, Galveston, TX, United States
}

Stanniocalcin, a glycosylated peptide hormone, first discovered in a bony fish has originally been shown to play critical role in calcium and phosphate homeostasis. Two paralogs of stanniocalcin (STC1 and STC2) identified in mammals are widely expressed in variety of tissues. This review provides historical perspective on the discovery of fish and mammalian stanniocalcin, describes molecular regulation of STC2 gene, catalogs distribution as well as expression of STC2 in tissues, and provides key structural information known till date regarding mammalian STC2. Additionally, this mini review summarizes pivotal functions of STC2 in calcium and phosphate regulation, cytoprotection, cell development, and angiogenesis. Finally, STC2's role as a novel marker for human cancers has also been outlined. Reviewing these studies will provide an opportunity to understand STC2's structure, biological functions as well as key molecular pathways involving STC2, which will help us design innovative therapeutic interventions

OPEN ACCESS

Edited by:

Susumu Hyodo,

The University of Tokyo, Japan

Reviewed by:

Satoshi Ogawa,

Monash University Malaysia, Malaysia Toshio Sekiguchi,

Kanazawa University, Japan

*Correspondence:

Aditya D. Joshi

adjoshi@utmb.edu

Specialty section: This article was submitted to Experimental Endocrinology, a section of the journal

Frontiers in Endocrinology

Received: 03 February 2020 Accepted: 10 March 2020

Published: 31 March 2020

Citation:

Joshi AD (2020) New Insights Into Physiological and Pathophysiological

Functions of Stanniocalcin 2.

Front. Endocrinol. 11:172.

doi: 10.3389/fendo.2020.00172 using this novel hormone.

Keywords: stanniocalcin 2, calcium regulation, development, angiogenesis, cytoprotection, apoptosis, tumor biology

\section{INTRODUCTION}

The stanniocalcin-historically known as hypocalcin, teleocalcin, or parathyrin-is a widely-expressed hormone that is speculated to function in an autocrine and/or paracrine manner $(1,2)$. Various studies have indicated the possible involvement of two mammalian stanniocalcins, namely stanniocalcin 1 and 2 (STC1 and 2), in diverse biological processes including calcium regulation, cell proliferation and apoptosis, inflammation, Endoplasmic Reticulum (ER)/oxidative stress, metabolism, and cancer (3-10). However, precise physiological functions and signaling pathways in which stanniocalcins are involved remain to be elucidated. Majority of previous studies and reports were centered on understanding role of STC1 in plethora of cellular and molecular functions (11-17). This mini review is entirely focused on depicting our current understanding of physiological and pathological role of STC2 within human health and disease context.

\section{DISCOVERY OF MAMMALIAN STANNIOCALCINS}

Stanniocalcin is a glycosylated, disulfide-linked, homodimeric hormone, first isolated from the corpus of stannous-a small endocrine gland in the kidney of teleostean and holostean fish (1, 2, 18-21). In 1964, Fontaine et al., "stannioectomized" (surgically removed) corpus of stannous and observed hypercalcemia along with decrease in sodium and chloride levels (22). Further studies identified stanniocalcin as a bonafide regulator of calcium entry through gills and intestine $(23,24)$. 
It was also shown that stanniocalcin mediated decrease in cAMP resulted in inhibition of calcium channels at gill epithelial cells (25). In 1986, Wagner et al. and Lafeber et al. successfully purified and characterized stanniocalcin from corpus of stannous of salmon and trout respectively $(2,20)$. However, no corpus of stannous or similar glands were identified in mammals and therefore it was assumed that stanniocalcin gene was lost during evolution. In 1996, Yoshiko et al. observed that the accumulation of cAMP induced by parathyroid hormone in ROS 17/2.8-5 cells was suppressed by $\mathrm{N}$-terminal synthetic stanniocalcin from Oncorhynchus keta (chum salmon) (26). These data for the first time demonstrated that the fish hormone, stanniocalcin has a biological activity in isolated rat cells and its biological function of calcium regulation is intact. The presence of mammalian stanniocalcin was confirmed by Reddel laboratory when first human and later mouse stanniocalcin cDNA were cloned (27, 28). The amino acid sequence of mammalian stanniocalcin is $61 \%$ homologous to that of fish stanniocalcin. In 1998, stanniocalcin 2 (STC2), a paralog of stanniocalcin (later renamed as STC1) was identified by two independent groups $(4,29,30)$. Ishibashi et al. cloned STC2 from human osteosarcoma cDNA library, whereas Reddel research group identified, cloned and characterized STC2 from both human and mouse. Human STC2 showed 34\% identity with human STC1 as well as with eel stanniocalcin (4).

\section{MOLECULAR REGULATION OF STC2 GENE}

Human STC2 gene is located on chromosome 5q35.1, whereas STC1 is located on chromosome 8 p21.2 (31). Both human and mouse STC2 contains 4 exons spanning $13 \mathrm{~kb}$ of DNA. It was observed that the exon-intron boundaries, distribution of cysteine residues and the glycosylation site were conserved between STC1 and 2 and subsequent genomic structure analysis indicated that both paralogs were derived from common ancestor gene (32). STC2 lacks the well-defined CAG repeats as well as the TATA box-like sequences present in the STC1 (4). Very few studies have interrogated genetic regulation of STC2. DiMattia's laboratory identified that in human breast carcinoma cell lines T-47D and MCF7-estrogen (E2), progesterone (P4), and retinoic acid (RA) receptors play critical role in the regulation of STC2 (33). Promoter analysis revealed absence of estrogen, progesterone, or RA receptor elements in the proximal promoter region of the STC2 gene indicating that regulation of STC2 by these upstream receptors is a secondary response (33). Chromatin immunoprecipitation studies indicated binding of Hypoxia inducible factor $1 \alpha(\mathrm{HIF} 1 \alpha)$ to the STC2 promoter which contains Hypoxia Response Elements (HRE) (7). This study confirmed STC2 as a HIF1 $\alpha$ target gene that promotes cell proliferation in hypoxia in human breast and ovarian cancer cells (34). HIF1 $\alpha$ induced STC2 expression is modulated by two cofactors namely, histone acetyltransferase p300 and histone deacetylase 7 (HDAC7) (34). Additionally, our laboratory showed Stc2 as an Aryl hydrocarbon Receptor (AhR) target gene containing Xenobiotic Response Elements (XRE) (35). Stc2 promoter contains 8
XREs clustered in a 250-bp region that was shown to recruit AhR by chromatin immunoprecipitation (35). Lastly, a study performed in mice deficient in klotho showed that klotho gene expression played important role in the regulation of renal Stc2 gene through the control of calcium and phosphorous concentrations (36).

\section{STRUCTURE, EXPRESSION, AND DISTRIBUTION OF STC2}

Human and mouse STC2 proteins are 302 and 296 amino acids in length respectively with first 24 residues predicted to be a signal peptide and remaining residues comprise the mature form of the hormone. STC2, a $56 \mathrm{kDa}$ protein has no sequence homology with parathyroid hormone (25). The hallmarks of STC2 are the cysteine residues conserved among family members and N-linked glycosylation consensus sequence (Asn-X-Thr/Ser) (Figure 1) (37). STC2 have 15 cysteines, whereas STC1 and fish stanniocalcin have 11 cysteines. The locations of first 10 cysteines are conserved within the stanniocalcin family. However, the 11th cysteine residue conserved between STC1 and fish stanniocalcin is not spatially conserved in STC2 (18). This cysteine plays crucial role in disulfide-linked homodimer formation (18). Therefore, it is predicted that the tertiary structure of STC2 might be different than that of STC1 and fish stanniocalcin. So far, no studies have shown a heterodimer formation between STC1 and STC2. STC2 is also phosphorylated by casein kinase 2 on its serine residues (38). The C-terminal of STC2 has a cluster of histidine residues $(\mathrm{HHxxxxHH})$, which may interact with divalent metal ions such as cobalt, copper, nickel, and zincthough the functional significance of this cluster remained to be studied (37). In mammals, investigation of tissue distribution of STC2 mRNA revealed its expression in variety of tissues including pancreas, heart, placenta, spleen, lung, kidneys, and skeletal muscles $(4,30,39)$. Additionally, abundant STC2 protein expression was observed in brain, lungs, liver, and kidneys $(4,30)$. An immunohistochemical study indicated STC2 expression and co-localization with glucagon-secreting alpha cells in pancreatic islets, strongly indicating STC2's involvement in glucose homeostasis (37). Additionally, various tumor cell lines specifically from lungs, colon, and mammary glands reported upregulated levels of STC2 (40-43).

Several reports suggest that STC2 is a secreted protein based on the findings with its paralog, STC1 (12). Human fibrosarcoma cell line, HT1090 has shown to secrete both STC1 and STC2 as phosphoproteins in the medium (38). Initial subcellular fractionation and immunogold labeling studies indicated localization of stanniocalcin to the inner mitochondrial matrix (12). In transfected COS cells, STC2 localization to the ER and Golgi apparatus was demonstrated-consistent with its secretary fate (5). This report however failed to overlap STC2 with mitochondrial markers in COS cells. Purified mitochondrial fractions were also devoid of any STC2 expression (5). Immunofluorescence studies performed on permeabilized mouse primary hepatocytes treated with cinnabarinic acid, an Aryl hydrocarbon Receptor agonist, to induce STC2 expression 


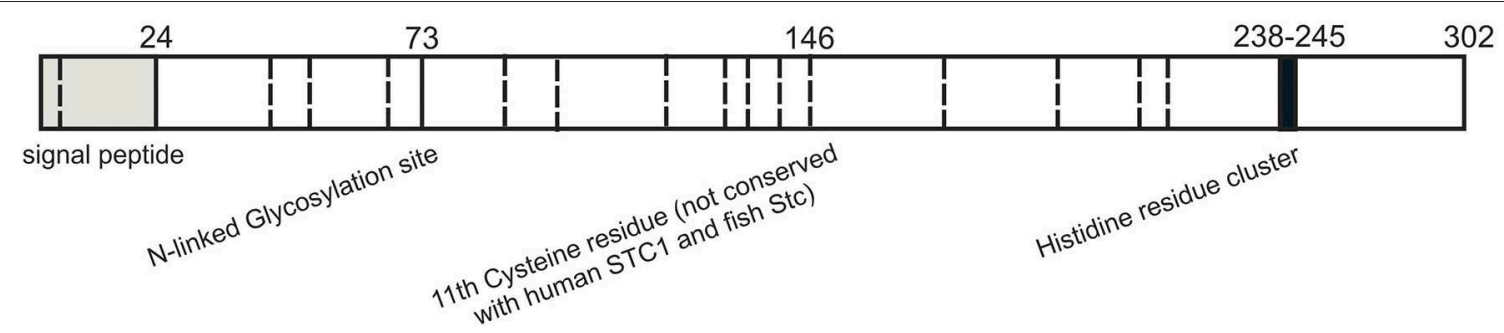

FIGURE 1 | Structural features of stanniocalcin 2. Schematic representation of the known functional residues of human STC2. Putative signal peptide sequence is shown in gray. $\mathrm{N}$-Glycosylation site is denoted with solid line and 15 cysteine residues are represented with dashed lines. Cluster of histidine residues $(\mathrm{HH} \times \mathrm{x} x \mathrm{HH})$ is in black.

revealed presence of STC2 prominently in ER based on colocalization with ER marker, KDEL (6). On contrary, nonpermeabilized hepatocytes displayed punctate staining of STC2 on cell surface. Confocal microscopy performed on liver sections also showed STC2 puncta associated with the plasma membrane based on the overlapping distribution with membrane marker pan-cadherin (6). Furthermore, a stanniocalcin-alkaline phosphatase (STC-AP) fusion protein was generated to identify and localize stanniocalcin receptor (12). In mouse outer medullary kidney sections, binding of STC-AP to thick ascending limb cells and collecting duct cells were observed. Mouse outer cortical kidneys showed specific punctate binding over distal convoluted tubules and collecting duct cells. Apical membrane staining was also noticed in proximal convoluted tubules. In liver, putative stanniocalcin receptor was present in hepatocytes as detected by punctate staining, especially on cell membranes near central vein (12). Therefore, based on the current immunological data, it is conceivable that STC2 is bound to the putative stanniocalcin receptor(s) and might function in an autocrine and/or paracrine fashion as speculated by various groups $(5,6,12,44)$.

\section{PHYSIOLOGICAL AND PATHOLOGICAL FUNCTIONS OF STC2 \\ Phosphate and Calcium Regulation}

Studies performed in cell lines have provided the evidence of STC2's involvement in kidney phosphate regulation. STC2 transfected $\mathrm{CHO}$ cells inhibited the promoter activity of type II sodium phosphate transporters, present on the apical membranes of kidney proximal tubules (4). Inhibition of type II sodium phosphate transporters resulted in reduction of phosphate uptake in opossum kidney cell lines (4). Therefore, current data suggests that STC2 inhibits phosphate transport through transcriptional regulation of phosphate transporter. Additionally, Stc2 expression was downregulated in mice with hypophosphatemia (Phex ${ }^{\mathrm{Hyp}}$ ), whereas mice on high-phosphate diet resulted in increased kidney Stc2 mRNA expression (4). These studies strongly indicate that STC2 may play critical role in phosphate metabolism. Additionally, STC2 overexpression in MC3T3 cells facilitated osteoblast differentiation and mineralization by regulation of ERK phosphorylation, suggesting
STC2's involvement in bone metabolism (45). Experiments performed in mouse embryonic fibroblasts cultured from Stc2 knockout animals displayed elevated levels of cytosolic calcium following ER calcium store depletion attributed to the increase in extracellular calcium influx through store operated calcium channels (9). Mouse embryonic fibroblasts that overexpress Stc2 attenuated store operated calcium entry. Zeiger et al. further showed that STC2 interacted with Stromal interaction molecule 1 (STIM1), an ER calcium sensor, which triggered store operated calcium channels following ER store depletion (9). STC2 interaction with STIM1-ORAI (encoded by Orai3, Calcium Release-Activated Calcium Modulator 3) and subsequent store operated calcium entry was also observed in mouse platelets, where STC2 altered non-capacitative calcium entry and platelet aggregation by modulating expression of ORAI3 channels (46).

\section{Role in Animal Development}

Both STC1 and 2 have been implicated in the regulation of tissue remodeling in mice (47-50). STC2 was specifically shown to attenuate ovarian progesterone biosynthesis via PKA pathway (51). The STC2 suppression of progesterone production was associated with the inhibition of follicle-stimulating hormone (FSH)-induced Cyplal and 3 $\beta$-hydroxysteroid dehydrogenase expression (51). STC2 also interacted with Ran-binding protein $M$ (RanBPM) and stimulated RanBPM-induced androgen receptor activation (52). Phenotypically STC2 overexpressed mice exhibit growth restriction, whereas knockout mice were larger than wild-type littermates $(53,54)$. Stc2 knockout mice were $10-15 \%$ larger and grew at a faster rate than its wildtype counterparts from four week onwards (53). On contrary, human STC2 transgenic mice were $45 \%$ smaller than wildtype littermates (54). STC2's negative regulation of postnatal growth was demonstrated by its ability to interact with pregnancy-associated plasma protein-A (PAPP-A), potentially inhibiting its proteolytic activity toward insulin-like growth factor binding protein 4 (IGFBP4) and causing reduction in insulin-like growth factor (IGF) signaling $(55,56)$. Recent genome-wide association studies identified rare height increasing alleles of STC2 with compromised proteolytic inhibition of PAPP-A and increased cleavage of IGFBP4 resulting in higher bioavailability of IGF (57). Additionally, STC2 mediated PAPPA inhibition was also demonstrated to ameliorate atherosclerosis in hypercholesterolemic mice (58). 


\section{Angiogenesis}

Both STC1 and 2 showed stimulatory effects on angiogenesis (59). STC2 overexpression in human umbilical vascular endothelial cells showed significant increase in cell cycle regulators-cyclin-D, phospho-retinoblastoma, matrix metalloproteinase 2 (MMP2), and decrease in tissue inhibitors of metalloproteases 1 (TIMP1). Furthermore, STC2 mediated angiogenic sprouting was due to activation of both Vascular endothelial growth factor/Vascular endothelial growth factor C (VEFG/VEGF2) and angiopoietin 2 pathways (59).

\section{Involvement in Cytoprotection}

First evidence of STC2's cytoprotective function was demonstrated by Thinakaran et al. (5), where STC2 was upregulated in N2a mouse neuroblastoma cell lines upon exposure to tunicamycin and thapsigargin induced ER stress. STC2 was also elevated in response to $\mathrm{H}_{2} \mathrm{O}_{2}$ induced oxidative stress and hypoxia (5). Both in $\mathrm{N} 2 \mathrm{a}$ and $\mathrm{HeLa}$ cell lines overexpression of STC2 protected cells from thapsigargininduced cell death (5). Human neural crest derived Paju cells transfected with STC2 showed increased resistance to ischemic challenge and thapsigargin induced stress (60). In mouse primary hepatocytes, activation of Aryl hydrocarbon Receptor by the tryptophan catabolite, cinnabarinic acid upregulated expression of STC2 to elicit cytoprotection against apoptosis induced by $\mathrm{H}_{2} \mathrm{O}_{2}$, thapsigargin and ethanol (6). Cinnabarinic acid treatment also provided protection against apoptosis and liver injury in mouse model of acute alcoholinduced hepatotoxicity. This in vivo cinnabarinic acid mediated cytoprotection was shown to be AhR-dependent and STC2 mediated albeit the exact pro-survival pathways downstream of STC2 need to be studied $(6,61)$. In a cerulean-induced pancreatitis mouse model, STC2 elevation was observed within four hours of initiating pancreatic injury (3). Elevated STC2 altered both protein kinase R (PKR)-like endoplasmic reticulum kinase (PERK) phosphorylation and activating transcription factor 4 (ATF4) levels though an undetermined mechanism and reduced acinar cell damage during pancreatic injury (3). In human adipose-derived mesenchymal stem cells (ADSC) and human mesenchymal stem cells isolated from umbilical cord blood (UCB-MSC) subjected to $\mathrm{H}_{2} \mathrm{O}_{2}$ induced oxidative stress, STC2 overexpression exhibited increased cell viability and survival. Upregulation of Cyclin-dependent kinase 2 and 4 (CDK2 and 4) as well as down-regulation of cell cycle inhibitors p16 and p21 were observed after STC2 transduction. STC2 overexpression also resulted in activation of pAKT and pERK1/2 signaling pathways to protect against oxidative stress induced apoptosis (62). Our group also observed that cinnabarinic acid mediated upregulation of STC2 can protect against microvesicular steatosis in alcoholic liver disease model (6). Similarly, Zhao et al. showed that STC2 ameliorated hepatosteatosis and hypertriglyceridemia in obese mice through the activation of Signal transducer and activator of transcription 3 (STAT3) signaling pathway (10). STC2 has also been involved in deregulation of glycaemia in obese mice as well as in type 2 diabetes mellitus patients (8). Additionally, it was speculated that STC2 might play role in glucose uptake and metabolism, glycogen storage and triacylglycerol synthesis in both brown and white adipose tissues $(44,63)$. Taken together STC2 exhibits pro-survival effect in various model systems.

\section{Tumor Biology}

The human STC2 gene has been mapped to 5q35.1, which is linked with tumor progression and metastasis $(31,37)$. STC2 expression has been associated with two essential conditions namely hypoxia and ER stress associated with tumor microenvironment $(5,7)$. Role of STC2 in human cancers has been studied from two different perspectives namely expression of STC2 in specific cancer models and cell lines, and STC2's function in cell growth, differentiation and apoptosis. Several reports suggest elevated expression of STC2 in human hepatocellular carcinoma, neuroblastoma, breast cancer, colorectal cancer, renal cell carcinoma, esophageal squamous cell cancer, and prostate cancer (41, 64-69). Additionally, expression of STC2 was correlated with tumor invasion, metastasis and size in gastric cancers and hepatocellular carcinoma (70). In gastric cancer patients, STC2 expression in circulating tumor cells as well as serum STC2 levels were positively correlated with pathological diagnosis and prognosis $(71,72)$. Study by Wang et al. indicated elevated levels of STC2 in hepatocellular carcinoma tissues and were related to tumor size and multiplicity of hepatocellular carcinoma (68). Both STC2 mRNA and protein expression were related to tumor size, stage, metastasis, and differentiation in hepatocellular carcinoma. The hepatocellular carcinoma patients with higher expression of STC2 also had shorter median survival time (68). Furthermore, ectopic expression of STC2 promoted hepatocellular carcinoma cell proliferation and colony formation. STC2 expression also regulated G1 to $S$ phase transition and altered protein levels of cyclin D1 and pERK1/2 suggesting direct role of STC2 in hepatocellular carcinoma progression and metastasis (70). In pancreatic cancer, STC2 expression was positively correlated with tumor size and lymph node metastasis and negatively correlated with 5 years survival rate studied in 98 case samples (73). Furthermore, overexpression of STC2 promoted the proliferation, migration, and invasion of pancreatic cancer by inducing epithelial-mesenchymal transition (73). In colorectal cancer, STC2 promoted the epithelial-mesenchymal transition of colorectal cells via AKT-ERK signaling pathway (40). STC2 overexpression was associated to nasopharyngeal carcinoma malignancy and poor prognosis including higher potential of progression and distant metastasis (74). Using CNE2 cell line model as well as tumor samples from 94 patients, it was shown that STC2 promoted post-radiation survival, migration, and invasion of nasopharyngeal carcinoma $(74,75)$. It was also reported that overexpression of STC2 promotes ovarian cancer growth as well as promotes tumorigenicity and growth in colon cancer (76). On contrary, knockdown of STC2 under hypoxic conditions reverses migration of colon cancer (77). STC2 has also been implicated in promoting head and neck squamous cell carcinoma metastasis via regulation of PI3K/AKT/snail signaling pathways (78). STC2 was also positively correlated with metastasis and progression of lung cancer (42), but surprisingly, a knockdown of STC2 in 




FIGURE 2 | Myriad functions of stanniocalcin 2. STC2 is predicted to function in an autocrine and / or paracrine fashion. STC2 interaction with a putative receptor is speculated based on current immunological data. Once internalized, STC2 plays critical roles in maintaining intracellular calcium and phosphate levels, cytoprotects against ER/oxidative stress induced apoptosis and maintains glucose homeostasis. STC2 is also an important component involved in vascular development, metabolism, animal development as well as in human cancers.

H460 lung cancer cell line attenuated hydrogen peroxide induced oxidative stress and ROS levels suggesting putative protective role of STC2 in redox regulatory system of lung cancer (42). STC2 also suppressed breast cancer cell migration and invasion by $\mathrm{PKC} /$ claudin 1 mediated signaling $(41,43)$. STC2 expression was also associated with positive outcome in male breast cancer (79). Taken together, except in breast cancer, STC2 expression is a potential prognostic marker for variety of cancers which promotes tumor cell growth, invasion and migration.

\section{CONCLUSIONS}

Originally discovered from Corpus of stannous in fish, stanniocalcin paralogs (STC1 and 2) have been identified and cloned from human and rodents and are expressed in almost all the mammalian tissues. Phylogenetic examination revealed that both STC1 and STC2 are evolved from a common ancestral gene and there is a possibility of identification of additional stanniocalcin-like agonists across eukaryotes. Biologically STC2 has been shown to play role in calcium regulation, ion transport, growth and development, cell protection, metabolism, angiogenesis, and oncology. Located in ER and Golgi apparatus, the STC2 hormone is predicted to exert its biological function through an autocrine and/or paracrine pathway. Direct molecular and cellular studies are warranted to determine STC2's secretary function as well as to detect its putative receptor. Apart from STC2's dimeric nature and presence of histidines predicted to be involved in divalent metal ion binding very little is known about its three-dimensional structure and interactions with other proteins. With STC2's direct correlation with variety of cancers, it is expected that forthcoming studies will help explore the function and regulatory mechanisms of STC2 in tumor progression and metastasis. With STC2's indispensable role in cytoprotection against ER/oxidative stress induced apoptosis it is also imperative to study molecular pathways associated with this protein (Figure 2). Finally, given STC2's involvement in intracellular calcium regulation and protection against steatosis, hypertriglyceridemia, ischemia, and hypertonic stresses its pathophysiological characterization will be helpful in designing clinically relevant therapeutic strategies against plethora of diseases.

\section{AUTHOR CONTRIBUTIONS}

The author confirms being the sole contributor of this work and has approved it for publication.

\section{FUNDING}

This work was supported by the National Institutes of Health, National Institute of Diabetes and Digestive and Kidney Diseases grants R01DK122028 and K01DK102514. 


\section{REFERENCES}

1. Lafeber FP, Schaefer HI, Herrmann-Erlee MP, Wendelaar Bonga SE. Parathyroid hormone-like effects of rainbow trout Stannius products on bone resorption of embryonic mouse calvaria in vitro. Endocrinology. (1986) 119:2249-55. doi: 10.1210/endo-119-5-2249

2. Wagner GF, Hampong M, Park CM, Copp DH. Purification, characterization, and bioassay of teleocalcin, a glycoprotein from salmon corpuscles of Stannius. Gen Comp Endocrinol. (1986) 63:481-91. doi: 10.1016/0016-6480(86)90149-8

3. Fazio EN, Dimattia GE, Chadi SA, Kernohan KD, Pin CL. Stanniocalcin 2 alters PERK signalling and reduces cellular injury during cerulein induced pancreatitis in mice. BMC Cell Biol. (2011) 12:17. doi: $10.1186 / 1471-2121-12-17$

4. Ishibashi K, Miyamoto K, Taketani Y, Morita K, Takeda E, Sasaki $\mathrm{S}$, et al. Molecular cloning of a second human stanniocalcin homologue (STC2). Biochem Biophys Res Commun. (1998) 250:252-8. doi: 10.1006/bbrc. 1998.9300

5. Ito D, Walker JR, Thompson CS, Moroz I, Lin W, Veselits ML, et al. Characterization of stanniocalcin. 2:a novel target of the mammalian unfolded protein response with cytoprotective properties. Mol Cell Biol. (2004) 24:9456-69. doi: 10.1128/MCB.24.21.9456-9469.2004

6. Joshi AD, Carter DE, Harper TA Jr, Elferink CJ. Aryl hydrocarbon receptor-dependent stanniocalcin 2 induction by cinnabarinic acid provides cytoprotection against endoplasmic reticulum and oxidative stress. $J$ Pharmacol Exp Therap. (2015) 353:201-12. doi: 10.1124/jpet.114.222265

7. Law AY, Lai KP, Ip CK, Wong AS, Wagner GF, Wong CK. Epigenetic and HIF1 regulation of stanniocalcin-2 expression in human cancer cells. Exp Cell Res. (2008) 314:1823-30. doi: 10.1016/j.yexcr.2008.03.001

8. Lopez JJ, Jardin I, Cantonero Chamorro C, Duran ML, Tarancon Rubio MJ, Reyes Panadero M, et al. Involvement of stanniocalcins in the deregulation of glycaemia in obese mice and type 2 diabetic patients. J Cell Mol Med. (2018) 22:684-94. doi: $10.1111 / \mathrm{jcmm} .13355$

9. Zeiger W, Ito D, Swetlik C, Oh-hora M, Villereal ML, Thinakaran G. Stanniocalcin 2 is a negative modulator of store-operated calcium entry. $\mathrm{Mol}$ Cell Biol. (2011) 31:3710-22. doi: 10.1128/MCB.05140-11

10. Zhao J, Jiao Y, Song Y, Liu J, Li X, Zhang H, et al. Stanniocalcin 2 ameliorates hepatosteatosis through activation of STAT3 signaling. Front Physiol. (2018) 9:873. doi: 10.3389/fphys.2018.00873

11. Luo CW, Kawamura K, Klein C, Hsueh AJ. Paracrine regulation of ovarian granulosa cell differentiation by stanniocalcin (STC). 1: mediation through specific STC1 receptors. Mol Endocrinol. (2004) 18:2085-96. doi: 10.1210/me.2004-0066

12. McCudden CR, James KA, Hasilo C, Wagner GF. Characterization of mammalian stanniocalcin receptors. Mitochondrial targeting of ligand and receptor for regulation of cellular metabolism. J Biol Chem. (2002) 277:4524958. doi: 10.1074/jbc.M205954200

13. McCudden CR, Majewski A, Chakrabarti S, Wagner GF. Co-localization of stanniocalcin-1 ligand and receptor in human breast carcinomas. Mol Cell Endocrinol. (2004) 213:167-72. doi: 10.1016/j.mce.2003.10.042

14. Serlachius M, Alitalo R, Olsen HS, Andersson LC. Expression of stanniocalcin-1 in megakaryocytes and platelets. Br J Haematol. (2002) 119:359-63. doi: 10.1046/j.1365-2141.2002.03916.x

15. Serlachius M, Andersson LC. Upregulated expression of stanniocalcin-1 during adipogenesis. Exp Cell Res. (2004) 296:256-64. doi: 10.1016/j.yexcr.2004.02.016

16. Sheikh-Hamad D, Bick R, Wu GY, Christensen BM, Razeghi P, Poindexter B, et al. Stanniocalcin-1 is a naturally occurring L-channel inhibitor in cardiomyocytes: relevance to human heart failure. Am J Physiol. (2003) 285:H442-8. doi: 10.1152/ajpheart.01071.2002

17. Zlot C, Ingle G, Hongo J, Yang S, Sheng Z, Schwall R, et al. Stanniocalcin 1 is an autocrine modulator of endothelial angiogenic responses to hepatocyte growth factor. J Biol Chem. (2003) 278:4765459. doi: 10.1074/jbc.M301353200

18. Hulova I, Kawauchi H. Assignment of disulfide linkages in chum salmon stanniocalcin. Biochem Biophys Res Commun. (1999) 257:2959. doi: 10.1006/bbrc. 1999.0466
19. Lafeber FP, Flik G, Wendelaar Bonga SE, Perry SF. Hypocalcin from Stannius corpuscles inhibits gill calcium uptake in trout. Am J Physiol. (1988) 254:R891-6. doi: 10.1152/ajpregu.1988.254.6.R891

20. Lafeber FP, Hanssen RG, Choy YM, Flik G, Herrmann-Erlee MP, Pang PK, et al. Identification of hypocalcin (teleocalcin). isolated from trout Stannius corpuscles. Gen Comp Endocrinol. (1988) 69:19-30. doi: 10.1016/0016-6480(88)90048-2

21. Lafeber FP, Perry SF. Experimental hypercalcemia induces hypocalcin release and inhibits branchial Ca2+ influx in freshwater trout. Gen Comp Endocrinol. (1988) 72:136-43. doi: 10.1016/0016-6480(88)90189-X

22. Fontaine M. [Stannius' Corpuscles and Ionic $(\mathrm{Ca}, \mathrm{K}, \mathrm{Na})$. of the Interior Environment of the Eel (Anguilla Anguilla L.)]. C R Hebd Seances Acad Sci. (1964) 259:875-8.

23. Fenwick JC, So YP. A perfusion study of the effect of stanniectomy on the net influx of calcium 45 across an isolated eel gill (1). J Exp Zool. (1974) 188:125-31. doi: 10.1002/jez.1401880112

24. So YP, Fenwick JC. In vivo and in vitro effects of Stannius corpuscle extract on the branchial uptake of $45 \mathrm{Ca}$ in stanniectomized North American eels (Anguilla rostrata). Gen Comp Endocrinol. (1979) 37:1439. doi: 10.1016/0016-6480(79)90101-1

25. Wendelaar Bonga SE, Pang PK. Control of calcium regulating hormones in the vertebrates: parathyroid hormone, calcitonin, prolactin, and stanniocalcin. Int Rev Cytol. (1991) 128:139-213. doi: 10.1016/S0074-7696(08)60499-4

26. Yoshiko Y, Kosugi T, Koide Y. Effects of a synthetic N-terminal fragment of stanniocalcin on the metabolism of mammalian bone in vitro. Biochim Biophys Acta. (1996) 1311:143-9. doi: 10.1016/0167-4889(95)00160-3

27. Chang AC, Dunham MA, Jeffrey KJ, Reddel RR. Molecular cloning and characterization of mouse stanniocalcin cDNA. Mol Cell Endocrinol. (1996) 124:185-7. doi: 10.1016/S0303-7207(96)03929-9

28. Chang AC, Janosi J, Hulsbeek M, de Jong D, Jeffrey KJ, Noble JR, et al. A novel human cDNA highly homologous to the fish hormone stanniocalcin. Mol Cell Endocrinol. (1995) 112:241-7. doi: 10.1016/0303-7207(95)03601-3

29. Chang AC, Reddel RR. Identification of a second stanniocalcin cDNA in mouse and human: stanniocalcin 2. Mol Cell Endocrinol. (1998) 141:959. doi: 10.1016/S0303-7207(98)00097-5

30. DiMattia GE, Varghese R, Wagner GF. Molecular cloning and characterization of stanniocalcin-related protein. Mol Cell Endocrinol. (1998) 146:137-40. doi: 10.1016/S0303-7207(98)00163-4

31. White KE, Biber J, Murer H, Econs MJ. Chromosomal localization of two human genes involved in phosphate homeostasis: the type IIb sodium-phosphate cotransporter and stanniocalcin-2. Somat Cell Mol Genet. (1998) 24:357-62.

32. Wagner GF, Dimattia GE. The stanniocalcin family of proteins. J Exp Zool A Comp Exp Biol. (2006) 305:769-80. doi: 10.1002/jez.a.313

33. Raulic S, Ramos-Valdes Y, DiMattia GE. Stanniocalcin 2 expression is regulated by hormone signalling and negatively affects breast cancer cell viability in vitro. J Endocrinol. (2008) 197:517-29. doi: 10.1677/JOE-08-0043

34. Law AY, Wong CK. Stanniocalcin-2 is a HIF-1 target gene that promotes cell proliferation in hypoxia. Exp Cell Res. (2010) 316:466-76. doi: 10.1016/j.yexcr.2009.09.018

35. Harper TA Jr, Joshi AD, Elferink CJ. Identification of stanniocalcin 2 as a novel aryl hydrocarbon receptor target gene. J Pharm Exp Therap. (2013) 344:579-88. doi: 10.1124/jpet.112.201111

36. Yahata K, Mori K, Mukoyama M, Sugawara A, Suganami T, Makino $\mathrm{H}$, et al. Regulation of stanniocalcin 1 and 2 expression in the kidney by klotho gene. Biochem Biophys Res Commun. (2003) 310:12834. doi: 10.1016/j.bbrc.2003.08.131

37. Moore EE, Kuestner RE, Conklin DC, Whitmore TE, Downey W, Buddle $\mathrm{MM}$, et al. Stanniocalcin 2: characterization of the protein and its localization to human pancreatic alpha cells. Horm Metab Res. (1999) 31:40614. doi: $10.1055 / \mathrm{s}-2007-978764$

38. Jellinek DA, Chang AC, Larsen MR, Wang X, Robinson PJ, Reddel RR. Stanniocalcin 1 and 2 are secreted as phosphoproteins from human fibrosarcoma cells. Biochem J. (2000) $350(\mathrm{Pt}$ 2):453-61. doi: 10.1042/bj3500453

39. Shin J, Sohn YC. cDNA cloning of Japanese flounder stanniocalcin 2 and its mRNA expression in a variety of tissues. Comparative 
biochemistry and physiology. A Mol Integr Physiol. (2009) 153:249. doi: 10.1016/j.cbpa.2008.11.014

40. Chen B, Zeng X, He Y, Wang X, Liang Z, Liu J, et al. STC2 promotes the epithelial-mesenchymal transition of colorectal cancer cells through AKT-ERK signaling pathways. Oncotarget. (2016) 7:71400-16. doi: 10.18632/oncotarget.12147

41. Hou J, Wang Z, Xu H, Yang L, Yu X, Yang Z, et al. Stanniocalicin 2 suppresses breast cancer cell migration and invasion via the PKC/claudin-1-mediated signaling. PLoS ONE. (2015) 10:e0122179. doi: 10.1371/journal.pone.0122179

42. Na SS, Aldonza MB, Sung HJ, Kim YI, Son YS, Cho S, et al. Stanniocalcin2 (STC2): A potential lung cancer biomarker promotes lung cancer metastasis and progression. Biochim Biophys Acta. (2015) 1854:66876. doi: 10.1016/j.bbapap.2014.11.002

43. Todd JR, Ryall KA, Vyse S, Wong JP, Natrajan RC, Yuan Y, et al. Systematic analysis of tumour cell-extracellular matrix adhesion identifies independent prognostic factors in breast cancer. Oncotarget. (2016) 7:6293953. doi: 10.18632/oncotarget.11307

44. Sarapio E, De Souza SK, Model JFA, Trapp M, Da Silva RSM. Stanniocalcin1 and-2 effects on glucose and lipid metabolism in white adipose tissue from fed and fasted rats. Can J Physiol Pharmacol. (2019) 97:91623. doi: 10.1139/cjpp-2019-0023

45. Zhou J, Li Y, Yang L, Wu Y, Zhou Y, Cui Y, et al. Stanniocalcin 2 improved osteoblast differentiation via phosphorylation of ERK. Mol Med Rep. (2016) 14:5653-9. doi: 10.3892/mmr.2016.5951

46. Lopez E, Gomez-Gordo L, Cantonero C, Bermejo N, Perez-Gomez J, Granados MP, et al. Stanniocalcin 2 regulates non-capacitative $\mathrm{Ca}(2+)$ entry and aggregation in mouse platelets. Front Physiol. (2018) 9:266. doi: 10.3389/fphys.2018.00266

47. Xiao LJ, Yuan JX, Song XX, Li YC, Hu ZY, Liu YX. Expression and regulation of stanniocalcin 1 and 2 in rat uterus during embryo implantation and decidualization. Reproduction. (2006) 131:1137-49. doi: 10.1530/rep.1.01100

48. Stasko SE, Wagner GF. Stanniocalcin gene expression during mouse urogenital development: a possible role in mesenchymal-epithelial signalling. Dev Dyn. (2001) 220:4959. doi: 10.1002/1097-0177(2000)9999:9999 <::AID-DVDY1086>3.0.CO;2-5

49. Stasko SE, Wagner GF. Possible roles for stanniocalcin during early skeletal patterning and joint formation in the mouse. J Endocrinol. (2001) 171:23748. doi: $10.1677 /$ joe. 0.1710237

50. Stasko SE, DiMattia GE, Wagner GF. Dynamic changes in stanniocalcin gene expression in the mouse uterus during early implantation. Mol Cell Endocrinol. (2001) 174:145-9. doi: 10.1016/S0303-7207(00)00394-4

51. Luo CW, Pisarska MD, Hsueh AJ. Identification of a stanniocalcin paralog, stanniocalcin-2, in fish and the paracrine actions of stanniocalcin-2 in the mammalian ovary. Endocrinology. (2005) 146:469-76. doi: 10.1210/en.2004-1197

52. Shin J, Sohn YC. Identification of Ran-binding protein $\mathrm{M}$ as a stanniocalcin 2 interacting protein and implications for androgen receptor activity. BMB Rep. (2014) 47:643-8. doi: 10.5483/BMBRep.2014.47.11.097

53. Chang AC, Hook J, Lemckert FA, McDonald MM, Nguyen MA, Hardeman EC, et al. The murine stanniocalcin 2 gene is a negative regulator of postnatal growth. Endocrinology. (2008) 149:2403-10. doi: 10.1210/en.2007-1219

54. Gagliardi AD, Kuo EY, Raulic S, Wagner GF, DiMattia GE. Human stanniocalcin-2 exhibits potent growth-suppressive properties in transgenic mice independently of growth hormone and IGFs. American journal of physiology. Endocrinol Metab. (2005) 288:E92-105. doi: 10.1152/ajpendo.00268.2004

55. Jepsen MR, Kloverpris S, Botkjaer JA, Wissing ML, Andersen CY, Oxvig C. The proteolytic activity of pregnancy-associated plasma protein-A is potentially regulated by stanniocalcin-1 and -2 during human ovarian follicle development. Hum Reprod. (2016) 31:866-74. doi: 10.1093/humrep/dew013

56. Jepsen MR, Kloverpris S, Mikkelsen JH, Pedersen JH, Fuchtbauer EM, Laursen LS, et al. Stanniocalcin-2 inhibits mammalian growth by proteolytic inhibition of the insulin-like growth factor axis. J Biol Chem. (2015) 290:34309. doi: 10.1074/jbc.M114.611665

57. Marouli E, Graff M, Medina-Gomez C, Lo KS, Wood AR, Kjaer TR, et al. Rare and low-frequency coding variants alter human adult height. Nature. (2017) 542:186-90. doi: 10.1038/nature21039
58. Steffensen LB, Conover CA, Bjorklund MM, Ledet T, Bentzon JF, Oxvig C. Stanniocalcin-2 overexpression reduces atherosclerosis in hypercholesterolemic mice. Atherosclerosis. (2016) 248:3643. doi: $10.1016 /$ j.atherosclerosis.2016.02.026

59. Law AY, Wong CK. Stanniocalcin-1 and -2 promote angiogenic sprouting in HUVECs via VEGF/VEGFR2 and angiopoietin signaling pathways. Mol Cell Endocrinol. (2013) 374:73-81. doi: 10.1016/j.mce.2013.04.024

60. Zhang K, Lindsberg PJ, Tatlisumak T, Kaste M, Olsen HS, Andersson LC. Stanniocalcin: a molecular guard of neurons during cerebral ischemia. Proc Natl Acad Sci USA. (2000) 97:3637-42. doi: 10.1073/pnas.97.7.3637

61. Joshi AD, Hossain E, Elferink CJ. Epigenetic regulation by agonist-specific aryl hydrocarbon receptor recruitment of metastasis-associated protein 2 selectively induces stanniocalcin 2 expression. Mol Pharm. (2017) 92:36674. doi: $10.1124 / \mathrm{mol} .117 .108878$

62. Kim PH, Na SS, Lee B, Kim JH, Cho JY. Stanniocalcin 2 enhances mesenchymal stem cell survival by suppressing oxidative stress. BMB Rep. (2015) 48:702-7. doi: 10.5483/BMBRep.2015.48.12.158

63. Sarapio E, Souza SK, Vogt EL, Rocha DS, Fabres RB, Trapp M, et al. Effects of stanniocalcin hormones on rat brown adipose tissue metabolism under fed and fasted conditions. Mol Cell Endocrinol. (2019) 485:817. doi: 10.1016/j.mce.2019.02.004

64. Kita $\mathrm{Y}$, Mimori $\mathrm{K}$, Iwatsuki $\mathrm{M}$, Yokobori $\mathrm{T}$, Ieta $\mathrm{K}$, Tanaka $\mathrm{F}$, et al. STC2: a predictive marker for lymph node metastasis in esophageal squamous-cell carcinoma. Ann Surg Oncol. (2011) 18:261-72. doi: 10.1245/s10434-010-1271-1

65. Meyer HA, Tolle A, Jung M, Fritzsche FR, Haendler B, Kristiansen I, et al. Identification of stanniocalcin 2 as prognostic marker in renal cell carcinoma. Eur Urol. (2009) 55:669-78. doi: 10.1016/j.eururo.2008.04.001

66. Tamura K, Furihata M, Chung SY, Uemura M, Yoshioka H, Iiyama $\mathrm{T}$, et al. Stanniocalcin 2 overexpression in castration-resistant prostate cancer and aggressive prostate cancer. Cancer Sci. (2009) 100:9149. doi: 10.1111/j.1349-7006.2009.01117.x

67. Volland S, Kugler W, Schweigerer L, Wilting J, Becker J. Stanniocalcin 2 promotes invasion and is associated with metastatic stages in neuroblastoma. Int J Cancer. (2009) 125:2049-57. doi: 10.1002/ijc.24564

68. Wang $\mathrm{Y}, \mathrm{Wu} \mathrm{J}, \mathrm{Xu} \mathrm{J}$, Lin S. Clinical significance of high expression of stanniocalcin-2 in hepatocellular carcinoma. Biosci Rep. (2019) 39:1-8. doi: 10.1042/BSR20182057

69. Zhang C, Chen S, Ma X, Yang Q, Su F, Shu X, et al. Upregulation of STC2 in colorectal cancer and its clinicopathological significance. Onco Targets Ther. (2019) 12:1249-1258. doi: 10.2147/OTT.S191609

70. Wang H, Wu K, Sun Y, Li Y, Wu M, Qiao Q, et al. STC2 is upregulated in hepatocellular carcinoma and promotes cell proliferation and migration in vitro. BMB Rep. (2012) 45:629-34. doi: 10.5483/BMBRep.2012.45.11.086

71. Arigami T, Uenosono $\mathrm{Y}$, Ishigami S, Yanagita S, Hagihara T, Haraguchi $\mathrm{N}$, et al. Clinical significance of stanniocalcin 2 expression as a predictor of tumor progression in gastric cancer. Oncol Rep. (2013) 30:283844. doi: $10.3892 /$ or.2013.2775

72. Fang Z, Tian Z, Luo K, Song H, Yi J. Clinical significance of stanniocalcin expression in tissue and serum of gastric cancer patients. Chinese J Cancer Res. (2014) 26:602-10. doi: 10.3978/j.issn.1000-9604.2014.10.08

73. Lin CSL, Huang S, Weng X, Wu Z. STC2 is a potential prognostic biomarker for pancreatic cancer and promotes migration and invasion by inducing epithelial-mesenchymal transition. Prev Early Detect Gastroint Cancers. (2019) 2019:9. doi: 10.1155/2019/8042489

74. Lin S, Guo Q, Wen J, Li C, Lin J, Cui X, et al. Survival analyses correlate stanniocalcin 2 overexpression to poor prognosis of nasopharyngeal carcinomas. J Exp Clin Cancer Res. (2014) 33:26. doi: 10.1186/1756-9966-33-26

75. He H, Qie S, Guo Q, Chen S, Zou C, Lu T, et al. Stanniocalcin 2 (STC2). expression promotes post-radiation survival, migration and invasion of nasopharyngeal carcinoma cells. Cancer Manag Res. (2019) 11:641124. doi: 10.2147/CMAR.S197607

76. Miyazaki S, Kikuchi H, Iino I, Uehara T, Setoguchi T, Fujita T, et al. Anti-VEGF antibody therapy induces tumor hypoxia and stanniocalcin 2 expression and potentiates growth of human colon cancer xenografts. J Int Cancer. (2014) 135:295-307. doi: 10.1002/ijc.28686 
77. Law AY, Wong CK. Stanniocalcin-2 promotes epithelial-mesenchymal transition and invasiveness in hypoxic human ovarian cancer cells. Exp Cell Res. (2010) 316:3425-34. doi: 10.1016/j.yexcr.2010.06.026

78. Yang S, Ji Q, Chang B, Wang Y, Zhu Y, Li D, et al. STC2 promotes head and neck squamous cell carcinoma metastasis through modulating the PI3K/AKT/Snail signaling. Oncotarget. (2017) 8:5976-91. doi: 10.18632/oncotarget.13355

79. Coulson-Gilmer C, Humphries MP, Sundara Rajan S, Droop A, Jackson $\mathrm{S}$, Condon A, et al. Stanniocalcin 2 expression is associated with a favourable outcome in male breast cancer. J Pathol Clin Res. (2018) 4:2419. doi: $10.1002 / \mathrm{cjp} 2.106$
Conflict of Interest: The author declares that the research was conducted in the absence of any commercial or financial relationships that could be construed as a potential conflict of interest.

Copyright $(\odot 2020$ Joshi. This is an open-access article distributed under the terms of the Creative Commons Attribution License (CC BY). The use, distribution or reproduction in other forums is permitted, provided the original author(s) and the copyright owner(s) are credited and that the original publication in this journal is cited, in accordance with accepted academic practice. No use, distribution or reproduction is permitted which does not comply with these terms. 